\title{
Health effects of wildfire smoke in children and public health tools: a narrative review
}

\author{
Stephanie M. Holm $\mathbb{1}^{1,2,3,4} \cdot$ Mark D. Miller ${ }^{1,2,4} \cdot$ John R. Balmes ${ }^{1,2,5}$
}

Received: 15 May 2020 / Revised: 7 September 2020 / Accepted: 11 September 2020 / Published online: 20 September 2020

(c) The Author(s) 2020. This article is published with open access

\begin{abstract}
Wildfire smoke is an increasing environmental health threat to which children are particularly vulnerable, for both physiologic and behavioral reasons. To address the need for improved public health messaging this review summarizes current knowledge and knowledge gaps in the health effects of wildfire smoke in children, as well as tools for public health response aimed at children, including consideration of low-cost sensor data, respirators, and exposures in school environments. There is an established literature of health effects in children from components of ambient air pollution, which are also present in wildfire smoke, and an emerging literature on the effects of wildfire smoke, particularly for respiratory outcomes. Low-cost particulate sensors demonstrate the spatial variability of pollution, including wildfire smoke, where children live and play. Surgical masks and respirators can provide limited protection for children during wildfire events, with expected decreases of roughly $20 \%$ and $80 \%$ for surgical masks and N95 respirators, respectively. Schools should improve filtration to reduce exposure of our nation's children to smoke during wildfire events. The evidence base described may help clinical and public health authorities provide accurate information to families to improve their decision making.
\end{abstract}

Keywords Children $\cdot$ Wildfire smoke $\cdot$ Health effects $\cdot$ Masks $\cdot$ Respirators $\cdot$ Schools

\section{Background}

There are an estimated 7.4 million children in the United States affected by wildfire smoke annually, many of them in the Southeast, Pacific Northwest, and California [1]. The increase in wildfires in recent years suggests that this population at risk has only grown. The single-day record for school closures due to wildfires (either direct effects or

$\triangle$ Stephanie M. Holm

stephanie.holm@ucsf.edu

1 Western States Pediatric Environmental Health Specialty Unit, University of California San Francisco, San Francisco, CA, USA

2 Division of Occupational and Environmental Medicine, University of California San Francisco, San Francisco, CA, USA

3 Division of Epidemiology, School of Public Health, University of California Berkeley, Berkeley, CA, USA

4 Children's Environmental Health Center, Office of Environmental Health Hazard Assessment, California Environmental Protection Agency, Oakland, CA, USA

5 Division of Environmental Health Sciences, School of Public Health, University of California Berkeley, Berkeley, CA, USA smoke related) was on November 15, 2018 when over 1 million California school children had classes canceled due to wildfires [2]. In parts of the USA, up to $20 \%$ of the fine particulate matter to which children are exposed results from wildfires [3, 4]. Due to our warming climate, the exposure to wildfire smoke is likely to only increase, with more children exposed to wildfire smoke as the century goes on [5].

There are health impacts of wildfire smoke in adults. According to a 2015 systematic review of the health effects of wildfire smoke on the general population, most epidemiologic research has been done on respiratory outcomes, with some on mortality and other outcomes as well [6]. Hospitalizations and emergency visits for respiratory diseases have been consistently increased with wildfire smoke exposure in adults although effect size estimates are variable both in how they are reported and in their magnitude [6-9]. There have been mixed results for cardiovascular outcomes [7, 10]. All-cause mortality is also associated with wildfire smoke exposure in adults [10]. A recent study in Washington state found an odds ratio of 1.013 (95\% CI 1.002-1.024) associated with a 1-day lag in wildfire smoke exposure (but not associated with any other lags from same day to a 4-day lag) [11]; respiratory deaths 
in middle aged adults were particularly increased with an odds ratio of $1.35(95 \%$ CI $1.09,1.67)$. The interested reader can find good summaries of wildfire effects in the general population in a few recent review papers $[6,12,13]$.

Problematically, very few studies have intentionally focused on pediatric populations as a target population or subpopulation [6]. Children are an especially vulnerable population because they have increased exposure (children often spend more time outdoors), they breathe more air relative to their body weight, and they are still growing and developing. They also have less nasal deposition of particles, meaning that a higher proportion of particles can penetrate deeply into the lungs [14]. Moreover, adverse effects on the developing lungs in childhood have been demonstrated to have health effects across the lifecourse [15].

A fact sheet providing public health guidance regarding wildfire smoke in children was assembled in 2007, and most recently updated in 2019 as a collaboration between the American Academy of Pediatrics, US Environmental Protection Agency (EPA) and Pediatric Environmental Health Specialty Units (PEHSUs) [16]; The American Lung Association has also created similar wildfire guidance for the public [17]. Yet, because of the lack of research in this area, there is a need for further certainty regarding the scientific underpinnings of wildfire smoke effects in children. There is also a paucity of guidance regarding ways to protect children's health if they have to be outdoors (i.e., when in transit to school). This paper attempts to fill that gap by compiling and summarizing the information needed for both public health and clinical decision-making regarding wildfire smoke exposure in children.

In the 'Health effects' section, this paper will first outline what is known about the components of wildfire smoke, mechanisms by which these components may cause health effects, and epidemiologic evidence of health effects from specific air pollutants that are contained in wildfire smoke. There is much more evidence for these health effects during non-wildfire smoke events, so that literature will be summarized first, as similar effects are likely from these components as a part of wildfire smoke. The paper then summarizes the epidemiologic literature specifically associating health effects with wildfire smoke exposure. Where available, we review published literature that provides data on associations of health effects with exposure to smoke from wildfires (primarily non-structural fires that are unplanned, sometimes also called forest fires, brush fires or bush fires) as well as from prescribed burns. We briefly touch on health effects of wildfires not specific to wildfire smoke.

In the 'Public health responses' section, this paper will review literature relevant to three different tools which may be useful to the development of policies to protect children from the effects of wildfire smoke: the use of low-cost sensor data for decision making, consideration of mask or respirator use in children, and minimizing exposures at schools. The paper concludes with summaries of the relative effects of different potential strategies for protecting children's health.

\section{Health effects of wildfire smoke in children}

Due to the paucity of evidence of health effects from wildfire smoke in children, it is important to consider knowledge that can be extrapolated from the relatively robust literature, relating health effects to specific air pollutants which occur in wildfire smoke (outside of wildfire exposure periods). Both short and long-term effects of pollutants will be discussed, both because wildfire smoke contributes to a child's total life-course exposure, and because as wildfires become more frequent, wildfires alone may be responsible for chronic exposures.

\section{Composition of wildfire smoke and potential health effects of specific pollutant components of wildfire smoke}

It is critical that we understand the components of wildfire smoke and how these are similar to and different from the components of ambient pollution. We know that the major components of wildfire emissions are organic and elemental carbons (which contribute to the concentration of particles) as well as gases, including carbon dioxide, carbon monoxide, nitrogen oxides, and volatile organic compounds (VOCs, such as formaldehyde and benzene) [18]. As fires reach the wildland urban interface, other toxic chemicals may be released from the burning of household or industrial goods, but how far these can disperse is much less well understood and they are likely to be relatively local concerns. It is worth noting that the smoke composition can vary with a number of factors, including the composition of the fuel being burned as well as the combustion type (flaming and smoldering) and efficiency [19]. Weather and atmospheric conditions also affect which compounds travel from the site of the fire, and therefore affect the exposures to the surrounding populace [12]. In addition, the concentration of high-surface area particulate matter in wildfire smoke may provide a substantial surface to which other toxic compounds can adsorb [20]. Primary components of wildfire smoke are also capable of reacting in the atmosphere to create secondary increases in other compounds (such as secondary organic aerosol and ozone [21]), but these secondary reactions can be even more difficult to predict due to the plethora of factors involved [19]. Although our ability to model the components of wildfire 
smoke has progressed in the last decade, there is still room for improvement [22].

Mechanistically, smoke can be expected to have respiratory effects due to direct deposition in the lungs leading to local oxidative stress and inflammation that can potentially spill over into the systemic circulation [12]. In fact, when wildfire PM was directly instilled into rodent lungs, the oxidative stress and inflammatory response generated were more robust than what occurred with instillation of other sources of PM [23]. Notably, wildfire air pollution is likely to have more potential to create oxidative stress relative to background pollution, due to the high level of polycyclic aromatic hydrocarbons (PAHs) and charged organic compounds released in high temperature combustion [7].

A large portion of wildfire smoke is particulate matter, with a higher proportion of ultrafine particles than typical ambient air pollution. It is well known that fine particulate matter $\left(\mathrm{PM}_{2.5}\right.$, particles $\leq 2.5 \mu \mathrm{m}$ in diameter $)$ deposit more deeply in the airways than larger particles, with more potential for adverse effects on the lungs as a result. Simulations of wildfire particle deposition suggest the same pattern holds for the particles within wildfire smoke; since many of the produced particles will be small, the risk of deposition deep in the respiratory tract is high, especially for children [24]. The recent EPA integrated science assessment of particulate matter described why children are particularly vulnerable to the effects of particulate pollution [25]. A robust literature exists linking particulate matter [26], particularly $\mathrm{PM}_{2.5}$, to respiratory admissions and asthma exacerbations in children [27]. There are also some data suggesting that exposure to pollutants may be a factor in the development of chronic lung diseases such as asthma, especially for traffic-related pollutants, including particulate matter [27, 28]. Prior work has also shown that not only is increasing exposure to particulate matter related to lower lung function in children, but that growth in lung function improves when ambient levels of those traffic-related pollutants are decreased [29]. This has critical importance, since adolescent and young adult lung function is predictive of respiratory health later in adult life. There is also substantial support in the literature for exposure to air pollution as a risk factor for lower respiratory infections, with multiple pollutants, including $\mathrm{PM}_{2.5}$, associated with increased rates of childhood pneumonia [30].

A growing body of literature also suggests that exposure to particulate matter may have neuropsychological effects in children, including associations with ADHD, autism, school performance, and memory [27, 31]. Animal studies indicate that the fraction of particulate matter, called ultrafine particles, which are $\leq 0.1 \mu \mathrm{m}$ in diameter, can penetrate into the systemic circulation and cross the blood-brain barrier [32].
Recent studies have also suggested that there may be metabolic or growth effects from exposure to particulate matter [27]. Adverse metabolic and growth effects can show up in multiple ways including decreases in birth weight, decreases in linear growth, and increases in obesity. Using data from a population-based survey in Indonesia, height at age 17 was related to prenatal particulate matter exposure despite controlling for a number of potential confounders, suggesting that particulate exposure might have long-term, overall health impacts [33]. A recent population-based retrospective cohort in China demonstrated that, on average, an IQR increase in whole pregnancy exposure to $\mathrm{PM}_{2.5}$ or $\mathrm{PM}_{10}$ decreased birthweight in term babies by $3 \mathrm{~g}$ or more [34]. Children who are exposed to higher levels of PAHs in utero have higher body weight than those with less exposure, with evidence of an exposure-response relationship [35]. These are particularly concerning findings given that early life exposure may act by "programming" fundamental metabolic, structural, and cell signaling mechanisms that may result in lifelong impacts. Children with these adverse metabolic and growth effects are likely to have poorer cardiovascular health as adults.

There are also higher levels of PAHs and VOCs [18] in wildfire smoke compared to ambient pollution. Many of these are known to be carcinogenic, including benzo(a) pyrene, formaldehyde, and benzene [27, 36, 37]. Some research has also linked exposure to VOCs with wheezing [36]. Given that wildfire exposures are recurring, these exposures could have important implications for lifetime cancer risk.

Some studies have suggested that particular windows of development are especially important for air pollution exposure. For example, second trimester $\mathrm{PM}_{2.5}$ exposure was associated with $\sim 2 \mathrm{mmHg}$ increases in systolic and diastolic blood pressure in childhood [38], suggesting that timing of exposure may be important. In a group of rhesus monkeys that was exposed in infancy to California wildfire smoke, lung function during adolescence was decreased in the entire group, and inflammatory markers were also changed, but these were in a sex-dependent fashion [3]. This study points to the potential for lifelong health impacts resulting from exposure to wildfire smoke early in life. Broadly, we know that environmental chemicals can have differing effects on lung development depending on the timing of exposure both in-utero and through childhood, with some effects persisting (or only becoming apparent after) many years [15]. This is a critical point for consideration of wildfire smoke exposures, as children at different stages of development may be differentially susceptible to the effects, but as yet we know of no research that investigated the timing or chronicity of wildfire smoke exposure in children. 
The particulate matter that is produced during wildfire events is more similar to biomass burning than to typical ambient air pollution in the USA. Much of the fine particulate air pollution in Southern California during nonwildfire events is made up of organic carbons, either those that are produced directly from combustion sources, or those made from secondary reactions of other pollutants (like volatile organics). When sampling was done during a wildfire episode, roughly 20 miles away from the fire, not only was the overall $\mathrm{PM}_{2.5}$ concentration increased, but the proportion made up of organic carbon compounds was higher than in typical ambient air pollution, making the particulate mixture more similar to biomass smoke in composition [37]. Thus, the robust field of knowledge regarding biomass smoke exposure to children in developing countries should be leveraged to understand possible effects of wildfire smoke exposure. Although these children generally have a different chronic exposure profile than children in the USA exposed to wildfire smoke, children who are exposed to biomass burning in their homes have consistently been found to have higher rates of lower respiratory infections and pneumonias [39]. Household biomass burning has also been associated with adverse birth outcomes in newborns [40]. As these are examples of chronic exposure to smoke that is similar in composition to wildfire smoke, they are worth considering in the discussion of wildfire smoke health effects.

A great deal is known about the composition of wildfire smoke, although it may be variable between fire events and over time and distance. There is an extensive literature suggesting that children will experience health effects from exposure to specific air pollutants that can occur in wildfire smoke, either from emissions or reactions of precursor components.

\section{Health effects studied in association with wildfire smoke}

As mentioned in the introduction, there are more studies describing health effects of wildfire smoke in adults than in children. This section focuses on the description of studies involving health effects in children specifically during wildfire periods. It is difficult to estimate pediatric exposures based on adult exposures because children have higher minute ventilation per kilogram of body weight, and therefore experience a higher dose of air pollution than adults. In addition, because children's systems are still growing and developing, they can be uniquely vulnerable to health effects of air pollutants. It is also difficult to compare results across different studies because there are many differences in the composition of wildfire smoke from different fires, as well as differences in how those exposures are quantified. Thus, when studies have included information on both children and adults, that information is included in this section, because within an individual study, the magnitude of these effects can be compared. This section will review the literature on health effects of smoke on children covering asthma, other respiratory symptoms, death, and pregnancy outcomes.

Similar to research involving exposure to ambient air pollution, the outcome category with the most robust literature involving exposure to wildfire smoke in children is respiratory effects. It has been demonstrated for over 25 years that pediatric asthma visits are increased in association with wildfire events [41]. Recently, Pratt et al. estimated the number of ER visits in children with asthma due specifically to exposure to ozone generated by wildfire emissions, and estimated that this accounts for more than 2000 ER visits in the USA annually [42]. In an HMO-based cohort in San Diego, it was demonstrated that during a wildfire in 2003, the worsening of asthma symptoms related to wildfire smoke exposure was modified by BMI, with obese children having the largest prevalence ratio for shortacting beta-agonist (SABA) prescriptions dispensed, 1.42 (1.12-1.80) [43]. Notably, this pattern was different during a 2007 fire in the same location, with all children having similar increases in SABA dispensing, regardless of BMI [43]. Following the 2003 Southern California wildfires, Delfino et al. found that age modified the relationship between wildfire $\mathrm{PM}_{2.5}$ and asthma visits with the strongest relationships found in children younger than five $(8 \%$ increase, 95\% CI 2-14) and the elderly (10\% increase, $95 \%$ CI 3-18), with nonsignificant changes in older children and adults [44]. Age was also found to modify the relationship between wildfire smoke exposure and ER wheezing visits in the 2007 fire season, with the strongest relationship between wildfire period and clinical visits for wheezing among Medicaid participants occurring in infants (RR 3.43 (95\% CI 1.49-7.38) compared to RR 1.39 for age 2-4 (95\% CI 0.41-3.76), RR 2.00 for age 5-17 (95\% CI 1.09-3.67) and RR 1.82 for ages 18-65 (95\% CI 1.24-2.67)) [45]. Using a complex modeling strategy to separate the smoke from wildfires from baseline $\mathrm{PM}_{2.5}$, increases in the smokeassociated $\mathrm{PM}_{2.5}$ were related to increases in asthma ER visits among children in Colorado (OR 1.08, 95\% CI $1.04-1.12$ per $1 \mu \mathrm{g} / \mathrm{m}^{3}$, OR for adults was $1.0995 \% \mathrm{CI}$ 1.06-1.12), but not visits for other respiratory diseases [46]. Thus, while pediatric asthma visits are increased overall, recent studies suggest that higher BMI and younger age may be important susceptibility factors.

Interestingly, a recent meta-analysis found that although both asthma ED visits and hospital admissions are increased with wildfire smoke exposure in children, the increase was smaller than for adults [47]. Furthermore, in a meta-analysis which explicitly compared effects of wildfire smoke on 
respiratory outcomes (including but not limited to asthma) in youth versus adults, the magnitude of effects was larger in adults, but with substantial heterogeneity in effects between studies [48].

The increase in asthma symptoms with wildfire smoke exposures is likely due to fine or ultrafine particles; wildfire $\mathrm{PM}_{10}$ is less consistently related to asthma symptoms. In fact, a pair of recent studies assessed asthma ER visits in Colorado for overlapping time frames; the study that used wildfire associated $\mathrm{PM}_{2.5}$ as the exposure metric found increased respiratory visits [46], whereas the one which used $\mathrm{PM}_{10}$ as the exposure did not find a relationship [8]. Three recent studies that used $\mathrm{PM}_{10}$ as their metric for assessing smoke exposure did not find associations with pediatric asthma [49-51], in contrast to the three recent studies of smoke exposure on pediatric asthma which used $\mathrm{PM}_{2.5}$ [44-46]. This may be because $\mathrm{PM}_{10}$ is not as good of an indicator of wildfire smoke exposure, because larger particles cause fewer health effects, or because of other methodologic differences with the studies.

In addition to asthma, wildfire events have been shown to influence other respiratory symptoms in children. Following a wildfire event in Southern California, those children who reported a longer duration of smoky smell being present indoors were more likely to report upper respiratory symptoms (such as itchy eyes, sore throat, cough, sneezing, or runny nose) as well as lower respiratory symptoms (like wheeze) [52]. In the Medicaid cohort for the 2007 San Diego wildfires, when controlling for individual characteristics, young children $(<5)$ also had increased healthcare visits for upper respiratory infections, pneumonia and bronchitis during the wildfire period, though older children did not [45]. Conversely, following a 2017 wildfire in San Diego, though pediatric respiratory visits were increased overall, the largest relative increase in respiratory visits at the university health system was actually for older children [53]. Interestingly, in that study, the regions with the highest risk for respiratory effects in children were those downwind from the fire within roughly 10 miles, suggesting that such areas could be prime targets for interventions. In a Spanish cohort, where children's symptoms were reported by the parent, during the wildfire period there was a statistically significant increase in itchy/watery eyes (OR 3.11, 95\% CI 1.62-5.97) and sore throat (OR 3.02, 95\% CI 1.41-6.44), comparing the period of the fire to immediately prior [54]. To summarize the non-asthma respiratory findings, children may experience upper respiratory effects related to wildfire smoke (such as eye, throat, and nose symptoms) and there may be increases in respiratory infections (like pneumonia) as well. Unsurprisingly, children close to, and downwind from, the fire are at highest risk.

Although the results from studies of wildfire smoke events show strong evidence of respiratory effects on children, smoke from controlled or prescribed burns may not have the same consequences. A group in Australia found no relationship between fine or coarse PM exposure from prescribed burns and severe asthma outcomes in children (initiation of oral steroids, healthcare visit or missing school); there was a relationship between symptoms and prescribed fire PM exposure, but interestingly the effect was $\sim 2 \%$ stronger in adults than in children (OR of 1.165 for increases in symptoms in adults $(95 \%$ CI 1.058-1.284) and OR 1.148 in children (95\% CI 1.042-1.264)) [55]. Notably, in this moderate sized study children of all ages and adults of all ages were grouped together, which could obscure some of the relationships in subgroups. This study also provided data suggesting that the lower exposures associated with prescribed burns are associated with less severe health effects than those from wildfires. This could be relevant for those areas of the USA, such as the Southeast, in which prescribed burns are a larger contributor to smoke exposures than wildfires [56]. However, there is very little published research in this area, making our knowledge of pediatric health effects from prescribed wildfires a true knowledge gap.

The recent study of mortality in Washington state associated with wildfires performed a sensitivity analysis in which deaths in children were assessed. The analysis is limited by the small number of deaths but suggests a possible effect of wildfire smoke exposure on respiratory deaths in young children (OR 1.52, 95\% CI 0.58-3.97) [11]. If this finding held in a larger sample, this would be a larger respiratory mortality effect in young children than in the next most affected group (middle aged adults, OR 1.35, 95\% 1.09-1.67) [11]. This finding was not statistically significant and no inferences should be made, but the strong point estimate suggests a potential association worthy of further exploration.

Several published studies have begun to explore the effects of wildfire smoke exposure on pregnancy outcomes. Using Colorado vital records data from 2007 to 2015, those exposed to wildfire smoke in the first trimester of pregnancy had babies with a decreased birth weight by $6 \mathrm{~g}$, and those exposed anytime during pregnancy had 1.076 times the odds of delivering preterm (95\% CI 1.016-1.139) [57]. An even larger administrative cohort in California, focused around the 2003 San Diego wildfires, found decreases in birth weight related to wildfire smoke exposure throughout pregnancy, with the largest effect in the second trimester, a decrease of $9.7 \mathrm{~g}$ (95\% CI - 14.5, -4.8) [58]; that study did not assess preterm birth. Small changes in birth weight are critically important as they can have lifelong cardiovascular implications; low birth weight is known to be an independent risk factor for adult cardiovascular disease [59].

As noted previously, there is an extensive body of evidence on the components of wildfire smoke. When making 
decisions to protect children from wildfire smoke, we should leverage the knowledge we have of health effects in children from these related bodies of literature. From the known health effects of specific pollutants in children, we expect that children would have similar health effects related to wildfire smoke. Estimated effects could be more severe than those from non-wildfire pollutants, given the increased potential for oxidative stress, but a wider body of literature is needed in order to compare effect estimates from wildfire and non-wildfire pollution. The comparison within studies of health effects in children compared to adults also suggests that effect estimates for many outcomes in adults (such as respiratory conditions) may be similar in magnitude to those in children, with particularly young children at higher risk. However, more studies directly comparing subpopulations of children and adults would allow for better comparisons in effect magnitudes.

\section{Health effects of other aspects of wildfire disasters}

It is important to note that wildfire smoke is not the only aspect of wildfires which may cause detrimental health effects in children. Because a wildfire event in a child's community may be a traumatic event, wildfires have been associated with a number of stress-related effects, including changes in infant feeding practices and high rates of psychiatric symptoms [60]. The mental health effects can be affected by personal characteristics of the children, social characteristics of the environment and the details of the disaster.

A number of studies suggest mental health effects of wildfire disasters on children. Surveys of the middle and high school students in a small Canadian city, 18 months after a large wildfire caused evacuation of the entire city, showed elevated rates of depressive symptoms among youth in that city compared to youth in a control city [61, 62]. It is worth noting, however, that these effects cannot be clearly attributed to wildfire smoke as the trauma associated with widespread evacuation likely contributes to mental health. Similarly, in a Californian cohort where all the families had been displaced by wildfires, both youth and parents reported high levels of stressors after the fires [63], and six months after a wildfire that damaged a portion of a school in Australia as well as some surrounding homes, nearly $50 \%$ of the students had symptoms consistent with post-traumatic stress disorder (PTSD) [64].

In a longitudinal cohort of adults in Australia, it has been demonstrated that other life stressors are important modifiers of the relationship between fire exposure and psychopathology, with those who have more stressors being both less likely to recover if they have major depression or PTSD early following a wildfire, and more likely to develop late symptoms if not present early on [65]. This, again, argues that much of the mental health effects related to wildfires may be mediated by stress rather than due to a specific toxicant exposure.

These findings serve as an important reminder to physicians, public health officials, parents, and others caring for children in the wake of wildfire events. Wildfire smoke can affect an incredibly large population of children, and the impact of wildfire smoke should certainly be mitigated as discussed below. But it is important to also consider the broader scope of impacts, especially for the smaller population of children who are more directly impacted by the wildfire itself.

\section{Tools for public health responses to wildfire smoke exposure in children}

Given the adverse effects of wildfire smoke for children shown in the previous section, it is crucial to consider how to minimize exposures to mitigate these health effects, particularly for children in disadvantaged communities. Guidance here is limited, as there have been few intervention studies regarding wildfire smoke exposures. In a questionnaire study following a Southern California wildfire, children who reported wearing masks, using air conditioning, or restricting outdoor time had less of an increase in symptoms with increasing days of exposure [52]. A study on the Hoopa Valley Indian Reservation in California found that in a real-life setting where multiple interventions were possible (mask wearing, portable air cleaner use, evacuation to a cleaner area) that only the duration of use of a portable HEPA air cleaner was associated with decreased symptoms [66]. The authors surmised that this could be related to the ease of using the air cleaner for the duration of the fire period, whereas mask use was subject to inconsistent wearing and poor fit and often people who evacuated the area did not do so for long.

With these results in mind, the second half of the current paper will explore three tools which may be useful as part of a public health response to protect children from the effects of wildfire smoke: the use of low-cost sensor data for decision making, consideration of mask or respirator use in children, and minimizing exposures at schools.

\section{Consideration of low-cost sensor data for decision making regarding children}

The availability of low-cost sensor data to the general public has drastically changed the perception of air quality monitoring, particularly in urban areas. Many members of the 
general public now expect data to show highly accurate spatial resolution, such as is shown on the maps displayed on the webpage affiliated with some of the low-cost sensor manufacturers. Yet, there is a lack of understanding that the data collected by the sensors may be different than that from regulatory monitors. In order to better leverage these data for decision-making there needs to be clarity on how to know which sensors are reliable and how to interpret the data from these sensors. This section will outline the evaluations of low-cost sensors by the Air Quality Sensor Performance Evaluation Center (AQ-SPEC) and describe some programs that have used sensor data to improve the spatial variability of estimated particulate matter concentrations. PM is an important component of wildfire smoke and the development of sensor technology is more advanced for PM compared to gaseous pollutants (as evidenced by third-party testing as described below), so we focus on the testing results for PM.

In the last few years, low-cost sensors for measurement of PM have improved tremendously. In 2014-2016, EPA scientists evaluated 13 different low-cost PM monitors. When the low-cost sensors were compared to values measured by federal reference monitors (FRM), they found $R^{2}$ values ranging from 0 to 0.77 for different sensors, meaning that the sensor readings explained anywhere from none to $77 \%$ of the variability in the true PM (FRM) concentrations [67]. Recently, the South Coast Air Management District has become the location for assessment of low-cost sensors, through their AQ-SPEC. Their webpage currently lists 49 low-cost particulate monitors that AQ-SPEC has assessed [68], with $R^{2}$ values for laboratory evaluations that range from 0.87 to 0.99 . However, $R^{2}$ values for real-world settings span a much wider range (0-0.98) [68]. Notably, 19 devices have $R^{2}$ values in the real-world that are 0.85 or greater for one or more PM fractions. Of those tested to date, only the Atmotube Pro, the Purple Air sensors (PA-I and PA-II) and the Sensirion Nubo have $R^{2}$ values that are $>0.85$ for both $\mathrm{PM}_{2.5}$ and $\mathrm{PM}_{1}$ in real-world situations [68].

Other efforts are underway to improve the interpretation of data from low-cost sensors. The California Air Resources Board (CARB, part of the California Environmental Protection Agency) has distributed a large number of low-cost sensors to air districts for placement in communities with historical pollution and/or exposure to wildfire smoke to indicate when and where more sophisticated monitoring instrumentation should be applied [69]. For one particular project CARB chose to purchase PurpleAir sensors based on results of sensor evaluations conducted by the AQSPEC. CARB is working to improve the accuracy of data produced by the sensors to bring reported values more in line with traditional regulatory air monitoring instrumentation [69]. Even though these sensors trend and track well with changes in particle concentration, experts recommend that the public use maps of low-cost sensor readings to get a sense of spatial variability, in order to compare to the regulatory monitors, rather than directly taking action based on the estimated PM concentration value from one particular sensor [69, 70]. The US EPA is working on a nationwide correction factor that may be used for data from PurpleAir monitors during wildfire events, to ease the interpretation of low-cost sensor data [70], and some scientists from Lawrence Berkeley National Laboratory recently published a wildfire correction factor paper [71].

In Oregon, the Department of Environmental Quality (DEQ) has been expanding their monitoring network with low-cost sensor-based monitors around the state, including at schools and city parks [72]. Their SensOR ${ }^{\mathrm{TM}}$ uses the same basic Plantower optical sensing component contained within the PurpleAir devices. They measure fine particulate matter from sources including residential wood burning, forest fires, slash burning, vehicle exhaust, and industrial and commercial emissions. Similar to work in California, they have also worked on improving the data processing to get values to better align with regulatory monitors. Each sensor is calibrated to a known standard, and regional correlation curves are applied at each monitoring site to correct the measurements to the Federal Reference Method (FRM). Federal monitors report out both concentrations and Air Quality Index values (AQI), an EPA scale which is used to translate concentrations into color-coded 'Levels of Concern' for communication to the public [73]. The Oregon network uses the EPA nowcast method [74] (with a 3-hour averaging time) to present AQI values to the public in near real time. The DEQ team has also worked with the Oregon Scholastic Athletic Association to use these calculated AQI values for decision-making regarding game and practice postponements or cancellations.

The City and County of Denver has been working on a major program to improve the spatial resolution of sensor data available for school decision-making, compared to the use of AirNow, which often only has a few monitors per metro area. AirNow is a partnership of multiple US federal government agencies, which measures and reports air quality data throughout the country using the color-coded AQI [73]. Denver applied for and received a large grant which they have used to establish their "Love My Air" program [75]. They have created a large network of lowcost sensors located at school sites, as well an online dashboard [76], and a monitor at each school site that displays the air quality data for that school community. The dashboards display an average value for the last $30 \mathrm{~min}$ and use guidance language based on the EPA Sensor Scale tools. They also have co-located their low-cost sensors with the state regulatory monitoring sites, and their low-cost network recalculates a correction factor based on these data every night. This system gives finely spatially resolved 
outdoor data for each of the participating schools but does not provide any indoor data. They have not yet developed plans for guidance based on the provided levels.

In addition to these state-level efforts, the federal EPA has done much work in this area. One of the concerns about the use of low-cost sensors is that the data are often reported nearly instantaneously, whereas regulatory values represent daily or annual averages. This can be particularly confusing for the public if sensor software converts an instantaneous estimated concentration to an "AQI value". Much of the research on the health effects of exposure to air pollution has also used average values over at least a day to relate to health outcomes, meaning that the health relevance of shortterm variations in pollutant levels (seconds to minutes) is unknown. This complicates the interpretation of continuously monitored data. The EPA has a pilot project [77] for interpretation of real-time sensor data, which breaks levels into a three-part scale (low, medium, and high), intended to reflect the probability that the 24-h level will exceed regulatory thresholds.

Because of the concerns outlined above, there remains substantial uncertainty for how to assess risk from shortterm peaks in particulate matter concentration. Most emerging low-cost sensor technology is focused on measuring particulate matter, and those measuring gaseous component of smoke are less reliable [68]. However, the benefits of increased spatial variability for decision-making regarding children are clear. Data from low-cost sensors can be used to compare to FRMs and estimate how a local concentration (at a school or home) might be different from the nearest reference monitor. The improvement in spatial variability could allow for decisions to be made that are site-specific, including the potential to move outdoor events to fields or parks where pollution is relatively less, or for individual schools as well as school districts to adjust their activities (e.g., bring recess indoors) in a site-specific manner based on their local conditions. It is important that programs which might help fund the use of low-cost sensors at schools consider distributing sensors in such a way as to include the children who are at highest risk of exposure, especially those with limited access to clean indoor spaces.

\section{Respirator use by children during wildfire events}

The use of masks or respirators has been a suggested strategy for respiratory protection for the general public during wildfire events. However, this is controversial, as use by the general public is very different from occupational use, which is the area in which we have the most knowledge. In general, guidance to date has discouraged the use of masks or respirators by children. However, in order to make public health guidance more evidence-based, it is important to discuss what degree of protection (if any) could be expected for different kinds of masks or respirators, both for the general public and children specifically. This section will define the difference between masks and respirators, discuss evidence that they are safe to wear, then describe expected decreases in exposure to particles from wearing cloth masks, surgical masks, and respirators, in both adults and children.

A filtering facepiece respirator (hereafter, a respirator) is a device which is designed to fit tightly to the face and filter inhaled particles [78]. In different countries, the testing procedures for these respirators are different, with corresponding slight differences in regulatory requirements. Despite this, many countries use similar respirators whose material filters $\sim 95 \%$ of particles, even though these respirators have different names (N95 in the US, FFP2 in European countries, KN95 in China, 1st class in Korea) [79]. By contrast a surgical mask is designed to minimize the excretion of droplets by the wearer and to protect from splashes of bodily fluids; they are not designed for filtration for the wearer [78]. As other types of masks (such as cloth face masks for the general public) are not regulated, it is unclear exactly for what these are designed.

\section{Common concerns}

One of the often raised concerns is that the use of masks may provide a false sense of security, if they do not provide adequate filtration and therefore protection [80]. This could be a concern, and argues for improved clarity of information to be provided to the public.

Another concern is that wearing respirators could have adverse physiologic effects. The majority of testing has been performed in small samples of healthy young adults, but the data suggest that the use of filtering facepiece respirators is unlikely to have meaningful physiologic effects. One of the early studies that looked at this was in a sample of only 10 young men, and found increased temperature inside the masks and consistent, slight increases in respiratory rate with N95 use [81]. Ten healthcare workers had no differences in physiologic measures during an hour of treadmill walking with a filtering facepiece respirator, compared to without [82]. Ten nurses who wore N95 masks for two 12-h shifts reported increased subjective symptoms, but without changes in blood pressure or blood oxygen levels; they did have slight increases in blood carbon dioxide levels (from 32.4 to 41.0) [83]. In a small group of healthy adults who performed treadmill walking for an hour, physiologic measurements were no different among filtering facepiece respirators with filter airflow resistance (often called pressure drop) across the respirator ranging from 3 to $9 \mathrm{~mm}$ of water [84]. In a population that included 
adults with mild respiratory disease, average ratings for discomfort were 10 or lower on a 6-20 scale, suggesting only mild discomfort [85], and average values of objectively measured heart rate, respiratory rate, and measures of lung function were within normal ranges for adults [86]. The highest ratings for discomfort for N95 respirators were for facial heat ratings. Data on whether N95 use can affect physiologic parameters in healthy pregnant people are mixed, though there is agreement that there is no effect on fetal heart rate [87]. Notably, in the presence of moderate particulate pollution, there is no evidence of worsening in cardiovascular physiologic parameters such as blood pressure and heart rate variability [88], and some evidence suggests they may actually improve, due to the beneficial effects of reducing pollutant exposure [89]. Nothing about pediatric physiology would make one concerned that children are at higher risk than adults for adverse cardiopulmonary effects. Thus, in individuals capable of removing a respirator should they get uncomfortable, concerns over physiologic effects should not prevent the general public from using respirators.

\section{Data regarding the use of non-respirator masks}

It is important to note that the protection provided by a mask (as well as a respirator) is a function of two main things: the filtration characteristics of the material and the fit of the mask on the face.

When various kinds of cloth have been tested for their filtration capability, it has been noted that the penetrance is highly variable by particle size, with smaller particles generally filtered less well [90]. When tested with fine and ultrafine sized $\mathrm{NaCl}$ particles (down to $20 \mathrm{~nm}$ ) using the NIOSH testing protocol, on average cloth masks decreased the particle penetrance by only $10 \%$, sweatshirts by $20-60 \%$, t-shirts by $14 \%$, towels by roughly $40 \%$, and scarves by roughly $10-25 \%$ [80]. Notably, there was actually less airflow resistance than the N95 material tested (which had a pressure drop of $9.5 \mathrm{~cm}$ of water), meaning that the user needs to generate less force in order to move air through the mask. In layman's terms, less airflow resistance means it would be easier to breathe. However, most of these airflow resistance tests were for single layers of the fabric, which is often not how something like a bandana or scarf face covering would be used by the public. The concern that the smallest particles might be filtered the least well is particularly important given that many of the particles produced by wildfire events are in the ultrafine range of particle sizes. In a study which tested the filtration capability against $\mathrm{PM}_{2.5}$ from volcanic ash, the mean filtration ranged from 18 to $72 \%$ for different fabric mask types [91], with a lot of variability within each category of fabric. In an urban setting in Indonesia, $\mathbf{P M}_{2.5}$ and $\mathrm{PM}_{10}$ were reduced on average by $30 \%$ and $70 \%$, respectively, when filtered through a surgical mask but the average change in $\mathrm{PM}_{2.5}$ when filtered through a bandana, hijab or motorcycle neoprene anti-dust mask was very close to zero [90]. For many of the bandanas, hijabs, or dust masks, $\mathrm{PM}_{2.5}$ concentration was substantially increased past the material, even if $\mathrm{PM}_{10}$ concentration was decreased. This was in the setting of $\mathrm{PM}_{2.5}$ exposures ranging up to $200 \mu \mathrm{g} / \mathrm{m}^{3}$ and $\mathrm{PM}_{10}$ ranging up to $5000 \mu \mathrm{g} / \mathrm{m}^{3}$. Overall, the filtration characteristics of cloth fabrics vary widely, and are expected to be least effective at filtering the smallest particles.

In addition to the filtration characteristics of the material, the fit of a mask made from a cloth material will affect the exposure received by a person wearing the mask. In a case report during the avian influenza epidemic, one group of researchers made a tight fitting cloth mask out of nine layers of a cotton t-shirt, and demonstrated an $85 \%$ decrease in the particles to which the wearer was exposed using quantitative testing methods [92]. Notably, they did not assess the airflow resistance (sometimes measured with pressure drop) across these many layers of fabric, though a different study showed that the pressure drop across two layers of a cotton $\mathrm{t}$-shirt was $5.1 \mathrm{~cm}$ of water [93]. However, when a group of healthy adults was instructed on making a homemade mask from cotton t-shirts, the median decrease in exposure from the homemade masks was $50 \%$ and $25 \%$ of the adults had no decrease in their exposure when wearing the homemade mask, whereas the median protection from a surgical mask was a decrease of $80 \%$ [93]. Similarly, a study that evaluated commercially available cloth masks found that the filtration efficiency for ultrafine diesel particles ranged from 10 to $80 \%$ depending on the size of the particle and the type of mask [94]. A bandana secured to a manikin reduced fine particulate sized saline aerosol by only $10 \%$ on average [95]. So while impressive reductions may theoretically be possible with masks from other materials, it would be unreasonable to expect those sorts of reductions consistently in the real world, unless a regulatory body were to start testing and providing standards for these mask types. In the absence of such a standard, cloth masks cannot be recommended to mitigate harm from wildfire smoke exposure, even if they have benefits for other applications, such as minimizing the spread of droplets during the COVID-19 pandemic.

A particular mask type to consider is surgical masks. Unlike ersatz cloth masks discussed above, surgical masks are standardized, and they are also often both available to purchase and less expensive than N95 respirators. It is clear that surgical masks do not provide the same level of respiratory protection as N95 respirators [96]; the question remains do they provide enough to be potentially beneficial? 
The first property to consider is again the filtration capability of the material. A NIOSH study of nine different dental or surgical masks found that the range of concentration decreases was 10-96\%, though the worst values were all for dental masks, with surgical mask material reducing concentrations by 62-96\% [97]. Conversely, testing done in Korea following the NIOSH protocol found that surgical masks decreased the concentration of $\mathrm{NaCl}$ droplets by only $40 \%$, while dental masks decreased them by $70 \%$ [98]. One group demonstrated that while penetrance of diesel exhaust particles through the material of three respirators tested ranged from 0.3 to $3.4 \%$, the penetrance through the material of a surgical mask was still only $20 \%$ (i.e., corresponding to a decrease of $80 \%$ ), suggesting that there may be more than expected benefit from the use of some surgical masks [99]. Surgical masks likely filter large particles even better, with only $13 \%$ of volcanic ash making it through the mask [91].

Given that surgical masks are not designed to seal tightly, the protection afforded by them would be expected to be much lower than their material's filtration characteristics. In a small study in the Netherlands, 28 adults and 11 children completed multiple tasks while wearing different mask types. In that small sample of children, the surgical mask reduced particulate matter inside the mask by $2 / 3$ or more [100]. In NIOSH testing, average decreases in exposure while wearing surgical masks ranged from 15 to $40 \%$ depending on the mask used [97]. A similar study testing fine $\mathrm{NaCl}$ particle exposures with manikins found that the surgical mask decreased exposure $33 \%$ on average [95]. An evaluation of surgical masks under actual breathing conditions, using a panel of healthy adults meant to imitate the NIOSH respirator testing panel, demonstrated that of the $\mathrm{NaCl}$ test particles in the environment, $\sim 30 \%$ leaked in around the edges of a surgical mask and 5-8\% came through the mask (Fig. 1) [101]. This was done by measuring the particle penetration on the human wearer and comparing to a mannequin with the mask glue-sealed to it and replicating the recorded breathing pattern of the human subject. In NIOSH testing that simulated real-world use, average surgical mask performance was not reported, however $95 \%$ of times a subject wore a surgical mask, they had a decrease of $17 \%$ or more in their particle exposure [96].

This literature highlights that while decreases in exposure related to surgical masks are variable and substantially less than respirators, the decreases may be enough to provide some health benefit for the public during wildfire seasons.

\section{Use of respirators by the general public}

Because N95 respirators are NIOSH-certified, by definition, their material filters out $95 \%$ of particles as small as $0.3 \mu \mathrm{m}$,

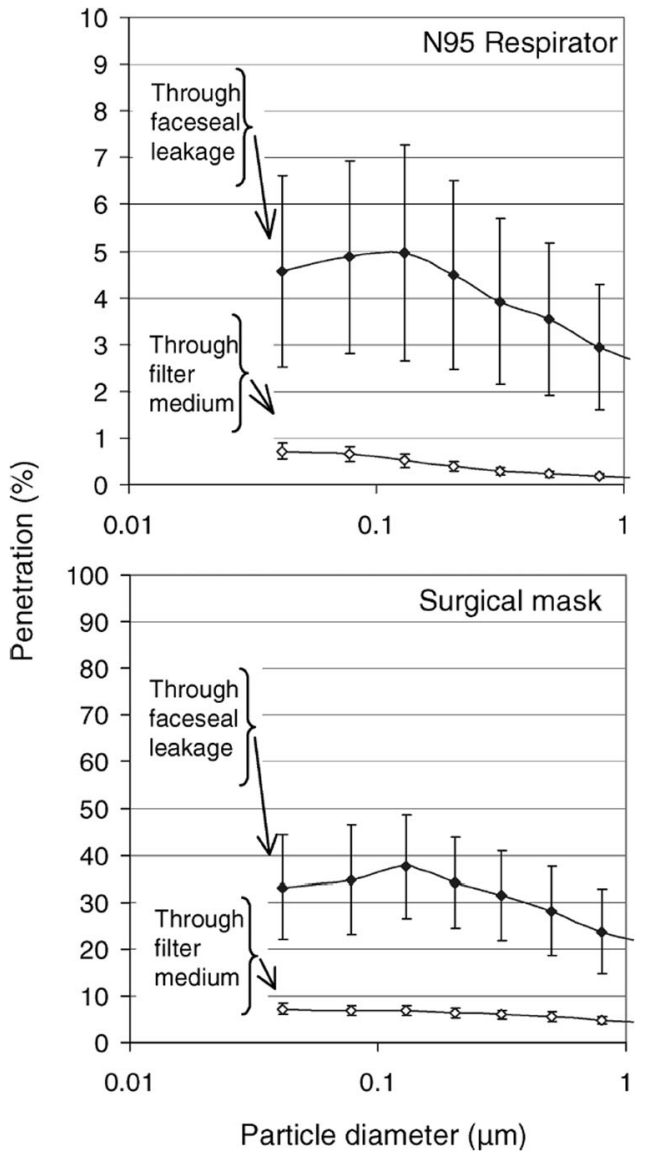

Fig. 1 How Particles Reach the Wearer of N95 Respirators and Surgical Masks. From Grinshpun et al. [101], demonstrating the percent of particles that leak through versus around surgical masks and respirators.

but fit remains important to the total exposure a wearer receives (see Fig. 1). In workplace settings, fit testing of respirators is required to ensure an adequate fit. However, previous work by NIOSH demonstrates that even respirators in the same category provide a wide range of protection, with some respirators providing superior protection without fit-testing than others do even with fit-testing [102]. Fittesting can thus be thought of as a way to ensure that all respirators in the category provide adequate protection, but the converse is not true; not all respirators require fit testing in order to ensure adequate protection.

Moreover, when testing $10 \%$ of the N95 respirators available in the USA in 1998 (18 masks), 95\% of people had $<34 \%$ of the exposure when wearing any of the respirators compared to no respirator, regardless of fit testing [102]. In 2007, 30 half-facepiece masks were tested and the protection was further improved, with $95 \%$ of people having $<30 \%$ of the exposure when wearing any of the respirators in the class [96]. While this amount of protection is likely inadequate for a worker who anticipates high lifetime exposure, in a situation where the general public is 
trying to temporarily reduce ambient exposure, such as with wildfire smoke, a $66-70 \%$ reduction in exposure for nearly everyone may be meaningful. In fact, in a general population cohort of non-fit-tested healthy adults, a crossover study in China found that there was less increase in airway inflammation (measured with exhaled nitric oxide) associated with air pollutant exposure when a study participant wore an N95, compared to wearing a sham N95 mask [103].

Other research supports the idea that non-fit tested populations may see benefits from respirator use when trying to temporarily reduce ambient exposure. A cohort of healthy women in China had slightly lower systolic blood pressure if wearing a non-fit tested respirator during mild exercise, and they also had more normal heart rate variability during a day in which the respirator was worn [99]. The same research group also found that adults with known cardiovascular disease also had improvements in both selfreported symptoms and indicators of cardiovascular health following the same protocol [104].

In a population which will not be fit tested, it is important to understand that masks or respirators for which there is more resistance to airflow (also known as higher pressure drop), will have more leakage around the mask when there is a poor fit [105]. However, work in general population cohorts has indicated that training people how to don respirators using videos can help the general public achieve fits nearly as good as those of occupational cohorts [106], and some specific N95 products achieve filtration nearly as good with or without fit testing [102]. In sum, even though respiratory protection from N95 or similar filtering facepiece respirators is maximized with fit testing, there would still likely be greater protection provided by a non-fit tested respirator than by other mask options [107].

In addition to indicating that $\mathrm{N} 95$ or similar respirators may be a good option to suggest for mitigating wildfire smoke exposure harms, the previous research reviewed above suggests that regulatory steps could be taken to improve protection of vulnerable individuals during poor air quality episodes as a result of wildfire smoke. For example, a regulatory process for respirators aimed at the general public could establish a minimum average fit factor required without fit testing.

\section{Use of respirators by children}

Given the evidence for respirator use in adults in wildfire smoke scenarios, the obvious question is whether the same holds true for children. A number of studies have looked at this question, and they generally support the idea that children could see benefits from respirators as well, despite the concern that fit may be difficult due to more variation in facial sizes.
In the Dutch paper mentioned above, 11 children (ages 5-11) performed tasks while the particles inside and outside of an adult N95 respirator were measured, and on average only $3-8 \%$ of the particles present outside the respirator were present inside [100]. The first published full evaluation of an N95 respirator designed for children was just published in the late 2019 [108]. In this paper, Goh et al. present data showing that in a sample of 106 healthy, Singaporean children aged $7-14$, all were able to achieve adequate mask fit using a quantitative mask fit test. Moreover, in their sample, the children had only small increases in end-tidal $\mathrm{CO}_{2}(5 \mathrm{mmHg}$ or less), suggesting negligible increases in the work of breathing.

In Korea, there is a KF80 standard for respirators, in addition to a KF94 standard (both of which are for the general public to use and are intended to decrease exposure by $80 \%$ or $94 \%$, respectively). As such, there are some "yellow sand" masks for children that are certified as meeting KF80 (yellow sand is the name for PM that periodically is present in high concentrations in Korea as a result of desert dust storms). Notably, one group that tested the filtration characteristics of a number of yellow sand masks for children found that those that were certified filtered out roughly $76 \%$ of the test saline aerosol, compared to $45 \%$ for those that were not certified [98].

Beyond these studies, a large respirator manufacturer in the USA has internal data suggesting that many adolescents have face sizes that fall within the range of adult face sizes for which N95 respirators are tested [109], and thus could potentially use existing products. Using an adult small-sized respirator, 22/28 school aged children were able to achieve a fit factor that reduced their exposure by $95 \%$, and nearly all children had a reduction of $80 \%$ or more. With modifications to specifically adapt the respirator for children, 58/ 61 children achieved an $80 \%$ reduction or more with assistance in donning only from their (untrained) parents [109]. Further, preliminary data on a child-specific respirator suggests that they may be able to achieve further reductions [109]. As these are preliminary and proprietary data, caution should be used in interpretation of these specific results. However, this and the few published papers mentioned above suggest that were the US government to certify child respirators, manufacturers would be able to produce a product that could offer substantial protection for children. Until such products are available, use of small adult size respirators could provide a decrease in exposure of $\sim 80 \%$ for children.

Overall, the existing literature suggests that the use of masks and respirators is safe in adults, and they would be expected to also be safe in children, though this is a research gap where further data would be useful. The use of cloth masks cannot be recommended at this time because the amount of exposure to particles inside a cloth mask is 
incredibly variable, with some cloth materials actually concentrating the particles and increasing exposures. Surgical masks also provide variable protection, but on average would be expected to provide a small (roughly 20\%) decrease in exposure for both children and adults. Non-fit tested N95 respirators would be expected to decrease exposure by roughly $80 \%$ for children and adults. There is a need for further regulatory action that could establish protection levels for licensing of products that can be used by the general public without fit testing; this could allow for higher levels of respiratory protection for the public, including children. Regulatory guidance on respiratory protection for children might also make it possible for public health groups to fund access to respirators, to help ease unequal access to these items based on cost.

\section{School guidelines and actions during wildfire events}

A large portion of a child's day is at school, and schools are a location where we can reach a large number of children with single interventions, making schools a particularly cost-effective option for preserving the health of children. Public schools also provide an opportunity to improve the equity of interventions because these schools are available to every child. This makes it crucially important that schools in underserved communities be prioritized for school-based interventions. However, we have a number of obstacles to making schools a safe and healthy location during wildfire smoke events.

Exposure to air pollution at school should be a concern during non-wildfire times as well as during wildfire smoke events. It has been noted that though there are only a handful of studies, the median $\mathrm{PM}_{2.5}$ levels in American schools are $17.5 \mu \mathrm{g} / \mathrm{m}^{3}$ outdoors and $15.2 \mu \mathrm{g} / \mathrm{m}^{3}$ indoors (using averaging times that were mostly 24-96 h) [27], above the annual regulatory guidance level of 12 [110]. These levels are even higher in other parts of the world, including many parts of Asia [27]. The median indoor PAH level in American schools was $1.0 \mathrm{ng} / \mathrm{m}^{3}$, despite WHO recommendations that no level is safe [27]. As these nonwildfire levels are of concern, we should anticipate that levels may be quite high during wildfire smoke events and work to reduce exposures to air pollution at all times in schools.

The US EPA has an indoor air quality toolkit for schools, with a seven-pronged framework for considering indoor air quality in schools: HVAC, moisture/mold, integrated pest management, cleaning and maintenance, materials selection, source control, and energy efficiency [111]. Consideration of these factors prior to wildfire season becomes even more important, as the ability for school to be a safer location for students during outdoor pollution events depends on these factors, which determine how much particulate matter is produced indoor as well as how much comes in from outside.

On average, $69 \%$ of outdoor PM makes it into people's homes, but the amount is widely variable based on a variety of factors [112]. Based on a small number of studies in North American schools, indoor air levels of $\mathrm{PM}_{2.5}$ are roughly $90 \%$ of the outdoor levels, with outdoor penetration suspected of being the major contributor, but again with much variability [27]. Indoor exposure is related to the amount of particles being produced indoors, the air exchange rate, the penetration of pollution through the structure, and particle loss rates [112]. Indoor sources of combustion (cooking, candles, and incense) as well as the use of any scented products (including air "fresheners") [113] should be minimized in classrooms. Special consideration should be used for locations within schools where large amounts of particles might be produced (e.g., cooking classes, woodshop, and art).

\section{Ventilation}

Ventilation is the rate at which outdoor air is supplied into an indoor space. Data from schools in California suggest relatively low ventilation rates in schools, with an average of less than half of the air being exchanged every hour [114]. This is a problem because of the presence of many indoor pollutants, including those from off-gassing of furnishings as well as from human activities (art supplies, woodshop activities, etc.). Further, modeling data suggest that $70 \%$ of these schools likely exceed the chronic reference concentration for formaldehyde based on these low ventilation rates [114]. Among recently renovated schools in Detroit, only $22 \%$ achieved minimum ventilation rates [115]. A review of the literature summarized studies in classrooms across North America, Europe, and Asia and found widespread evidence of inadequate ventilation [116]. Notably, many classrooms with recently retrofitted HVAC systems still had inadequate ventilation (especially those with wall-mounted units), often related to filters needing to be changed, disuse of the fan during the time the classroom was in use, or improper installation [117].

Measurements across 162 classrooms in 28 California schools demonstrated a relationship between classroom ventilation (using continuous measurements of $\mathrm{CO}_{2}$ for 2 years) and absences due to illness, with a decrease in absences of $\sim 1.5 \%$ for every $1 \mathrm{~L}$ per second per person increase in the ventilation (IRR 0.982, 95\% CI 0.968-0.997) [118]. In a crossover field study in Denmark, 10-12-year-old children had improved performance on math tasks when the ventilation rate in their classroom was doubled, even when controlling for temperature changes. 
The speed with which math tasks were completed increased roughly $20 \%$ (for example, on subtraction tasks students completed 1.94 subtraction tasks per minute at low ventilation with a 0.49 increase at high ventilation $(95 \% \mathrm{CI}$ 0.37-0.61) ) [119]. The results of these two studies suggest that improved ventilation in schools would be beneficial for children independent of wildfire smoke considerations.

\section{Filtration interventions generally}

Another strategy for managing air quality in indoor spaces is the use of filtration devices. Twenty-seven percent of homes with children with asthma report using air filtration as an asthma management strategy [120], and reviews of studies that have used either whole house filtration or portable HEPA air cleaners in patient's homes have suggested decreases in asthma symptoms when these are in use [121-123].

The known benefits of air filtration in homes and the large population of children spending time in schools suggests that this is a potentially cost-effective intervention that could provide significant benefit. However, the use of either improved central air filtration or portable HEPA air cleaners in classrooms has not been studied or discussed nearly as much as in individual homes. One study modeled the expected effects on asthma in school children in Detroit, if all classrooms had MERV filters with a rating of 12 or higher installed in their HVAC systems, and reported an anticipated decrease of $13 \%$ in $\mathrm{PM}_{2.5}$ attributable asthma morbidity (including a decrease in asthma hospitalizations from 8 to 6 and in asthma ER visits from 130 to 94) [124]. In that study the authors noted a relatively low cost $(\sim \$ 60$ per classroom), including the cost of the actual filter and slight increases in expenditure due to increased energy consumption. A pilot study in three Los Angeles elementary schools located in neighborhoods with substantial industry and traffic-related air pollution demonstrated decreases of up to $90 \%$ in the indoor fine and ultrafine particles with an increase in the filter used in the HVAC system from MERV7 to MERV16 [125]. In California, CARB has been working on a project to increase the MERV filter rating of filters in all schools. The building code was also amended in California, such that starting in 2020, new buildings must now have a MERV filter rating of 13 , rather than 6 , a substantial increase in filtration efficiency [126].

Implementation of filtration via central systems may not be possible in all cases. Some classrooms or school buildings do not have centralized air delivery, and even those with central air may not be able to upgrade to a high enough MERV rating. Depending on the characteristics of the central air system it may or may not be able to generate enough air flow to force air through a higher rated filter, which creates more air flow resistance. If central air filtration is not possible, filtration would need to occur via a stand-alone air cleaning device. However, even filtration by stand-alone devices may have benefits. In a single classroom with the HVAC system turned off (to simulate a classroom without HVAC), a MERV16 filter in a portable air cleaner demonstrated similar removal of contaminants compared to its use in the HVAC [125]. A recent study in Spain demonstrated marked decreases in particulate matter concentrations in two school gymnasiums when portable air cleaners were run [127]. Unfortunately but not surprisingly, that study found that the air cleaners were much less effective when the windows were open. This is of particular concern for wildfire season, as classrooms without HVAC systems may need to open windows for airflow in order to maintain a comfortable temperature.

A randomized controlled trial in urban American schools found that classrooms in which a set of four portable HEPA air cleaners were installed had significantly lower $\mathrm{PM}_{2.5}$ and black carbon levels, even though baseline levels before filtration were already low [128]. A recent evaluation of schools that had portable HEPA air cleaners installed in all student spaces found that schools with the air cleaners had standardized test scores that were 0.2 standard deviation (95\% CI 0.04-0.36) higher than those without, controlling for a number of factors [129]. Notably, HEPA air cleaners with ionizers are NOT recommended as the ozone produced by these can worsen asthma symptoms [121]. Air cleaners which produce no more than minimal ozone can be identified using the CARB List [130]. Notably, HEPA air cleaners are rated by clean air delivery rate, which should match the size of the room for which they are being used [131]. Also, the noise level of HEPA air cleaners is variable, and schools might consider prioritizing the purchase of quieter systems as these may be less likely to be turned off because of interference with normal classroom operations.

Though ventilation is important, greater improvements in health effects related to VOCs and particulate matter would be expected if filtration interventions are implemented alone compared to ventilation alone [114]. This would be expected to be especially true during a wildfire smoke event, when increased ventilation without filtration improvements could increase the quantity of particles reaching the indoors.

\section{Ventilation and/or filtration interventions during wildfire smoke events}

The only studies available of filtration interventions specifically during wildfire smoke events occurred in households rather than schools. Modeling data for Southern California suggests that having the HVAC system in a household run continuously can decrease wildfire PM by 24\% [132]. These decreases are further improved by adding a higher filtration efficiency filter into the HVAC system and 
running a portable air cleaner, for a total reduction of $62 \%$; running a portable air cleaner in a home without central air would be expected to decrease wildfire PM by $45 \%$ [132]. In four pairs of homes, in which one had a portable air filter installed, those with air filters had an $~ 60-80 \%$ decrease in the indoor PM levels [133]. It is worth noting, however, that these were all volunteers and the intervention was not randomly assigned, suggesting that this benefit could be overestimated. A cohort of 17 Canadian homes in which levels were measured during a forest fire, with and without the portable air cleaner, found that the mean decrease from the air cleaner use was $65 \%$. Although this study also used volunteers, the results seem much less susceptible to bias based on the study design and random allocation of when the filter was used [134]. As noted earlier, in a study of several interventions used in a real-world setting in Hoopa, California, only portable air cleaner use was associated with decreased symptoms [66].

\section{Current practices at schools for decision-making regarding mitigation of air pollution health effects}

One of the key considerations when assessing the need for activity modifications and school closures is whether the school or home environments will offer a cleaner air environment for students, teachers, and staff [135]. Currently, many local school districts use only publicly available EPA AirNow outdoor air data when making school closure or activity modification decisions. For example, 2019 guidelines from the Office of Environmental Health Hazard Assessment of the California EPA suggest basing decisions for outdoor activities on the AQI [136]. Though there are also suggestions for indoor air quality, there are not specific levels mentioned indoors. Uniquely, the Washington State Department of Health has made school guidance based on both outdoor and indoor levels in the schools [137], suggesting that both indoor and outdoor levels be used for making decisions on when to modify activities or close school, though guidance about how to measure or assess indoor levels remains sparse.

\section{Current practices at schools for mitigating wildfire smoke health effects}

In Washington State, the Department of Health has been working on a pilot project to incorporate low-cost sensor data for school decision-making during wildfires. They are exploring strategies for how local areas could operationalize their use, in a technically sound and cost-effective manner [138]. They have collaborated with local health jurisdictions to deploy two stationary low-cost sensors (one indoor in a communal space such as a library, one outdoor) at school sites for 2 weeks, either prior to or during wildfire season.
They also took a snapshot of measurements throughout the classrooms with a portable handheld device. They used these combined data to calculate an indoor/outdoor ratio for the communal area in each school and used the handheld device to document the range of indoor concentrations for the school relative to the communal space. The intent is that each school can then use its unique indoor/outdoor ratio to approximate the indoor levels using data from local regulatory monitors, and potentially use this information in decision-making. This solution has the advantage of being relatively low cost for a school district (it does not require a large fleet of monitors) and relatively easy for someone not trained in air pollution to use.

This approach does have some potential drawbacks. From a staffing standpoint, it relies on having capacity to do this sort of assessment either prior to or during wildfire season. This method assumes that the school has a regulatory monitor nearby that reflects the school's outdoor conditions; how well this site reflects school concentrations would depend on a number of factors including topography, distance to the sensor, and local sources of air pollution. This technique currently assumes that the particle penetration into the school would be similar during wildfire events to data collected during non-wildfire times, though as more data are collected this modeling technique could be refined. Because ultrafine particles (a major component of wildfire smoke) are filtered the least well [139], more would be expected to pass through the filter during wildfire smoke events compared to non-wildfire times. In addition, as filters get clogged during large pollution events such as wildfires, there would also be an increase in particles bypassing the filter. Specific characteristics of a school's HVAC system could also impact how the HVAC system performs (and thus how much particulate matter comes in and out) during wildfire events [140]. Data collected in two University of California Berkeley buildings during the 2018 Camp Fire suggest that, in a building with natural ventilation only, the median indoor/outdoor ratio increased from 0.39 during ambient conditions to 0.65 during the period of wildfire smoke; in the mechanically ventilated building, the median indoor/outdoor ratio increased even more substantially, from 0.01 to 0.24 [141, 142].

In sum, states and school districts can evaluate schools proactively for the ability to safely maintain operations during an extreme air event, establish "clean air shelter schools", and prioritize funding for upgraded air handling systems using this information. Ideally, an indoor air plan would include changing HVAC filters to the highest MERV rating that the system can handle, and providing non-ozone producing portable air cleaners in any spaces without HVAC systems. School staff can use data from low-cost sensors to assess spatial variability of particles in their area. For use during high air pollution events, including wildfires, 
a battery-operated low-cost sensor could be used to assess the relative indoor and outdoor concentrations of particles at a school site.

\section{Discussion}

There is clearly anxiety among the general population about how best to protect children during wildfire smoke episodes. In February of 2020, an online search found 18 different masks available to purchase in the USA that were marketed as providing respiratory protection in children. As we consider possible interventions for wildfire response and how to present them to the public, we should consider ways to reduce the pollutants in the surrounding environment, ways to decrease the personal exposure to pollutants, as well as ways to decrease personal susceptibility to the effects of air pollutants [143].

Modeling techniques have suggested that if individuals in a community take steps to decrease their exposure to wildfire smoke, based on predictions of an increase in $\mathrm{PM}_{2.5}$ in their area of $20 \mu \mathrm{g} / \mathrm{m}^{3}$ or more, asthma-related ED visits can be expected to decrease [144]. However, in order to do this, we, as a society, need to know what interventions to take, both for ourselves and our children. Though many have begun to suggest potential interventions [145], data on the risks and benefits of these have been generally scarce. In addition, more detailed exposure monitoring during wildfire events, including measuring a wider variety of pollutants (most studies continue to use particles as the primary or only measure) and evaluation of how mixtures affect children's health is needed. As access to clean indoor spaces is important for decreased wildfire smoke exposure, children from disadvantaged communities (which may not have funds for filtration in their schools or homes) are likely to experience more severe health effects than children from communities with more resources.

Based on our review of the literature, we advise that ventilation and filtration be improved in all buildings in which children spend time, including homes and schools. During wildfire smoke events, when pollutant levels reach levels that are unhealthy for sensitive groups (including children), actions should be taken to minimize children's exposure. The least exposure would occur from relocating to an area without wildfire smoke exposure, but this is likely not practical, particularly on a large scale. Evacuation can also be associated with adverse effects, especially in terms of mental health. The next best option to reduce exposure would be to remain indoors in a location with good ventilation and filtration using a MERV12 or better (70-80\% reduction) [121, 122], or at a minimum good filtration ( $\sim 50 \%$ reduction) [121]. One cost-effective way of ensuring that all children have access to a safe indoor location for at least a portion of their day is for our schools to have clean air. If no such location is available, there would still be some reduction $(\sim 30 \%)$ [112] in exposure from simply staying inside with windows closed. While driving, air should be recirculated in the car for an expected decrease of $\sim 80 \%$ while the windows are closed [146]. If a child has to be outdoors, or exposed to outdoor air, their exposure would likely be decreased the most ( 80\%) [100, 102, 109] by wearing a small size N95 respirator, ideally one that has been designed specifically for children (not yet available, but it they were, these might have reductions up to $95 \%$ if worn correctly) [108, 109]. These benefits would only be expected for short durations, however, as decreases of that magnitude depend on the respirator being worn correctly with minimal fidgeting. There may also be some minor benefit to wearing a surgical mask ( $20 \%$ reduction) [97, 100]. Masks made of other materials (bandanas, scarves, etc.) are unlikely to provide benefit when considering the small ultrafine particles that are a large component of wildfire smoke. Children should NEVER wear a mask if the mask or its parts could be a choking hazard, if they report difficulty breathing with the mask, or if they are unable to remove the mask on their own.

Despite uncertainties about the exact risks from exposure to wildfire smoke, there is clear evidence it poses significant risks to children's health. Any public recommendations should consider potential ethical and equity issues [147]. Questions arise since there is limited data on the effectiveness of face masks in children. In addition, their use may create a false sense of security leading to behavior that increases exposure unnecessarily. On the other hand, there is some evidence that even N95 masks not ideally fitted and surgical masks provide some level of protection. Though shelter in place with good quality air filtration is an ideal solution, not everyone will be able to follow this rule at all times (e.g., medical appointments). These and other considerations create a conundrum for public health messaging. Guidance that creates face mask use as a standard response raises concerns about availability, cost, and distribution of masks. Providing accurate information and advice to allow families to improve their decision making based on benefits and risks, including the resources each family has available is an ethical and respectful response. Failure to provide accurate and helpful information to the public may increase mistrust of public health agencies.

Children are particularly susceptible to environmental hazards that they inhale, as they breathe more per kilogram of weight than adults and are also more active (and therefore breathing faster). It is therefore expected that the health effects of wildfire smoke would be greater for children than adults. So far the data on this are mixed with many studies showing smaller effect in children compared to adults [47], 
but within children the youngest seem most vulnerable [44, 45]. Children also have the potential for long-term health effects from repeated high exposures during wildfires (given that they hopefully have many years of life ahead of them), though this has not yet been studied. There are also health outcomes (i.e., birth outcomes) that are unique to children, and for which early data suggest a possible effect of wildfire smoke.

Wildfires produce many ultrafine particles, which may be particularly relevant for health effects, but the change in the number of ultrafine particles might be underestimated when measuring these as part of the $\mathrm{PM}_{2.5}$ or $\mathrm{PM}_{10}$ fractions. Because larger particles are heavier than ultrafine particles, a small change in the mass of $\mathrm{PM}_{2.5}$ or $\mathrm{PM}_{10}$ could reflect either a small change in larger particles or a large increase in the ultrafine particles. Because the mass measurements do not differentiate, but the smaller particles can penetrate to the alveoli and ultrafine particles can have systemic distribution by crossing the alveolar-capillary membrane, mass measurements of large particle sizes might obscure impressive increases in the quantity of ultrafine particles that could reach the systemic circulation. Since many of the extant studies have used $\mathrm{PM}_{10}$ or $\mathrm{PM}_{2.5}$ in exposure assessments, we may actually be underrecognizing the health effects of wildfire smoke [7].

Thus, it is crucially important that we not only continue to work to better understand the health effects of wildfire smoke in children, but also that we bring regulatory bodies and stakeholders together now to act to mitigate the health effects that are already established.

Acknowledgements This review article was supported by the cooperative agreement award number 1 NU61TS000296-01-00 from the Agency for Toxic Substances and Disease Registry (ATSDR). Its contents are the responsibility of the authors and do not necessarily represent the official views of the Agency for Toxic Substances and Disease Registry (ATSDR). The US Environmental Protection Agency (EPA) supports the PEHSU by providing partial funding to ATSDR under Inter-Agency Agreement number DW-75-95877701. Neither EPA nor ATSDR endorse the purchase of any commercial products or services mentioned in PEHSU publications. The views expressed by the authors are their own and do not necessarily represent those of the Office of Environmental Health Hazard Assessment, the California Environmental Protection Agency, or the State of California. The authors would like to thank Martha Berger, Susan Stone, and Alison Clune at the US EPA for their tireless championing of this topic generally and this review paper specifically. The authors would also like to heartily thank the following individuals who took time from their busy schedules to share unpublished information about ongoing projects or analyses: Charles Pearson at the California Air Resources Board; Daniel Johnson at Oregon Department of Environmental Quality; Michael Ogletree at the Denver Department of Health and Environment; Nikki McCullough and Geoff Betsinger of $3 \mathrm{M}$ and Julie Fox, Nancy Bernard and Orly Stampfer of the Washington Department of Health. Finally, the authors would also like to thank the following individuals for their assistance in locating key references and resources: Nnenna Okoye of the UCSF Occupational and Environmental Medicine Residency, W. Rengie Chan of the Indoor Environment
Group at Lawrence Berkeley National Laboratory; and Maryann D'Alessandro, Lewis Radonovich and Jonathon Szalajda of NIOSH.

\section{Compliance with ethical standards}

Conflict of interest The authors declare that they have no conflict of interest.

Publisher's note Springer Nature remains neutral with regard to jurisdictional claims in published maps and institutional affiliations.

Open Access This article is licensed under a Creative Commons Attribution 4.0 International License, which permits use, sharing, adaptation, distribution and reproduction in any medium or format, as long as you give appropriate credit to the original author(s) and the source, provide a link to the Creative Commons license, and indicate if changes were made. The images or other third party material in this article are included in the article's Creative Commons license, unless indicated otherwise in a credit line to the material. If material is not included in the article's Creative Commons license and your intended use is not permitted by statutory regulation or exceeds the permitted use, you will need to obtain permission directly from the copyright holder. To view a copy of this license, visit http://creativecommons. org/licenses/by/4.0/.

\section{References}

1. Rappold AG, Reyes J, Pouliot G, Cascio WE, Diaz-Sanchez D. Community vulnerability to health impacts of wildland fire smoke exposure. Environ Sci Technol. 2017;51:6674-82.

2. Chalupka S, Anderko L. Climate change and schools: implications for children's health and safety. Creat Nurs. 2019;25:249-57.

3. Black C, Gerriets JE, Fontaine JH, Harper RW, Kenyon NJ, Tablin F, et al. Early life wildfire smoke exposure is associated with immune dysregulation and lung function decrements in adolescence. Am J Respir Cell Mol Biol. 2017;56:657-66.

4. Liu JC, Mickley LJ, Sulprizio MP, Dominici F, Yue X, Ebisu K, et al. Particulate air pollution from wildfires in the western US under climate change. Clim Change. 2016;138:655-66.

5. Mills D, Jones R, Wobus C, Ekstrom J, Jantarasami L, St. Juliana A, et al. Projecting age-stratified risk of exposure to inland flooding and wildfire smoke in the united states under two climate scenarios. Environ Health Perspect. 2018; 126:047007.

6. Liu JC, Pereira G, Uhl SA, Bravo MA, Bell ML. A systematic review of the physical health impacts from non-occupational exposure to wildfire smoke. Environ Res. 2015;136:120-32.

7. Black C, Tesfaigzi Y, Bassein JA, Miller LA. Wildfire smoke exposure and human health: significant gaps in research for a growing public health issue. Environ Toxicol Pharmacol. 2017;55:186-95.

8. Alman BL, Pfister G, Hao H, Stowell J, Hu X, Liu Y, et al. The association of wildfire smoke with respiratory and cardiovascular emergency department visits in Colorado in 2012: a case crossover study. Environ Health. 2016;15:64.

9. Shusterman D, Kaplan JZ, Canabarro C. Immediate health effects of an urban wildfire. West J Med. 1993;158:133-8.

10. Cascio WE. Wildland fire smoke and human health. Sci Total Environ. 2018;624:586-95.

11. Doubleday A, Schulte J, Sheppard L, Kadlec M, Dhammapala R, Fox J, et al. Mortality associated with wildfire smoke exposure in 
Washington state, 2006-2017: a case-crossover study. Environ Health. 2020;19:4.

12. Adetona O, Reinhardt TE, Domitrovich J, Broyles G, Adetona AM, Kleinman MT, et al. Review of the health effects of wildland fire smoke on wildland firefighters and the public. Inhal Toxicol. 2016;28:95-139.

13. Reid Colleen E, Brauer M, Johnston Fay H, Jerrett M, Balmes JR, Elliott Catherine T. Critical review of health impacts of wildfire smoke exposure. Environ Health Perspect. 2016;124:1334-43.

14. Bennett WD, Zeman KL, Jarabek AM. Nasal contribution to breathing and fine particle deposition in children versus adults. $\mathrm{J}$ Toxicol Environ Health A. 2007;71:227-37.

15. Miller MD, Marty MA. Impact of environmental chemicals on lung development. Environ Health Perspect. 2010;118:1155-64.

16. Hauptman M. Protecting children from wildfire smoke and ash. PEHSU. 2018. pehsu.net/_Library/facts/PEHSU_Protecting Children_from_Wildfire_Smoke_and_Ash_FACT_SHEET.pdf. Accessed 12 Mar 2020.

17. Wildfires. Am. Lung Assoc. https://www.lung.org/our-initia tives/healthy-air/outdoor/emergencies-and-natural-disasters/w ildfires.html. Accessed 23 Mar 2020.

18. Voulgarakis A, Field RD. Fire influences on atmospheric composition, air quality and climate. Curr Pollut Rep. 2015;1:70-81.

19. Jaffe D, Briggs N. Ozone production from wildfires: a critical review. Atmos Environ. 2012;51:1-10.

20. Ristovski ZD, Miljevic B, Surawski NC, Morawska L, Fong $\mathrm{KM}$, Goh F, et al. Respiratory health effects of diesel particulate matter. Respirology. 2012;17:201-12.

21. Brey SJ, Fischer EV. Smoke in the city: how often and where does smoke impact summertime ozone in the United States? Environ Sci Technol. 2016;50:1288-94.

22. Wilkins JL, Pouliot G, Foley K, Appel W, Pierce T. The impact of US wildland fires on ozone and particulate matter: a comparison of measurements and CMAQ model predictions from 2008 to 2012. Int J Wildland Fire. 2018;27:684-98.

23. Wegesser TC, Franzi LM, Mitloehner FM, Eiguren-Fernandez A, Last JA. Lung antioxidant and cytokine responses to coarse and fine particulate matter from the great California wildfires of 2008. Inhal Toxicol. 2010;22:561-70.

24. Schöllnberger H, Aden J, Scott BR. Respiratory tract deposition efficiencies: evaluation of effects from smoke released in the cerro grande forest fire. J Aerosol Med. 2002;15:387-99.

25. US EPA National Center for Environmental Assessment RTPN, Sacks J. Integrated Science Assessment (ISA) for Particulate Matter (Final Report, 2019). https://cfpub.epa.gov/ncea/isa/ recordisplay.cfm?deid=347534. Accessed 7 May 2020.

26. Guarnieri M, Balmes JR. Outdoor air pollution and asthma. Lancet. 2014;383:1581-92.

27. Oliveira M, Slezakova K, Delerue-Matos C, Pereira MC, Morais $\mathrm{S}$. Children environmental exposure to particulate matter and polycyclic aromatic hydrocarbons and biomonitoring in school environments: a review on indoor and outdoor exposure levels, major sources and health impacts. Environ Int. 2019;124:180-204.

28. Khreis H, Kelly CE, Tate J, Parslow R, Lucas K, Nieuwenhuijsen M. Exposure to traffic-related air pollution and risk of development of childhood asthma: a systematic review and meta-analysis. Environ Int. 2017;100:1-31.

29. Gauderman WJ, Urman R, Avol E, Berhane K, McConnell R, Rappaport E, et al. Association of improved air quality with lung development in children. N Engl J Med. 2015;372:905-13.

30. Nhung NTT, Amini H, Schindler C, Kutlar Joss M, Dien TM, Probst-Hensch N, et al. Short-term association between ambient air pollution and pneumonia in children: a systematic review and meta-analysis of time-series and case-crossover studies. Environ Pollut. 2017;230:1000-8.

31. Suades-González E, Gascon M, Guxens M, Sunyer J. Air pollution and neuropsychological development: a review of the latest evidence. Endocrinology. 2015;156:3473-82.

32. Schraufnagel DE. The health effects of ultrafine particles. Exp Mol Med. 2020;52:311-7.

33. Tan-Soo J-S, Pattanayak SK. Seeking natural capital projects: forest fires, haze, and early-life exposure in Indonesia. Proc Natl Acad Sci USA. 2019;116:5239-45.

34. Guo P, Chen Y, Wu H, Zeng J, Zeng Z, Li W, et al. Ambient air pollution and markers of fetal growth: a retrospective populationbased cohort study of 2.57 million term singleton births in China. Environ Int. 2020;135:105410.

35. Rundle A, Hoepner L, Hassoun A, Oberfield S, Freyer G, Holmes D, et al. Association of childhood obesity with maternal exposure to ambient air polycyclic aromatic hydrocarbons during pregnancy. Am J Epidemiol. 2012;175:1163-72.

36. Montero-Montoya R, López-Vargas R, Arellano-Aguilar O. Volatile organic compounds in air: sources, distribution, exposure and associated illnesses in children. Ann Glob Health. 2018;84:225-38.

37. Na K, Cocker DR. Fine organic particle, formaldehyde, acetaldehyde concentrations under and after the influence of fire activity in the atmosphere of Riverside, California. Environ Res. 2008; 108:7-14.

38. Rosa MJ, Hair GM, Just AC, Kloog I, Svensson K, PizanoZárate ML, et al. Identifying critical windows of prenatal particulate matter (PM2.5) exposure and early childhood blood pressure. Environ Res. 2020;182:109073.

39. Balmes JR. Household air pollution from domestic combustion of solid fuels and health. J Allergy Clin Immunol. 2019;143:1979-87.

40. Patel AB, Meleth S, Pasha O, Goudar SS, Esamai F, Garces AL et al. Impact of exposure to cooking fuels on stillbirths, perinatal, very early and late neonatal mortality - a multicenter prospective cohort study in rural communities in India, Pakistan, Kenya, Zambia and Guatemala. Matern Health Neonatol Perinatol. 2015;1. https://doi.org/10.1186/s40748-015-0019-0.

41. Chew FT, Ooi BC, Hui JKS, Saharom R, Goh DYT, Lee BW. Singapore's haze and acute asthma in children. Lancet. 1995;346:1427.

42. Pratt JR, Gan RW, Ford B, Brey S, Pierce JR, Fischer EV, et al. A national burden assessment of estimated pediatric asthma emergency department visits that may be attributed to elevated ozone levels associated with the presence of smoke. Environ Monit Assess. 2019;191:269.

43. Tse K, Chen L, Tse M, Zuraw B, Christiansen S. Effect of catastrophic wildfires on asthmatic outcomes in obese children: breathing fire. Ann Allergy Asthma Immunol. 2015;114:308-311.e4.

44. Delfino RJ, Brummel S, Wu J, Stern H, Ostro B, Lipsett M, et al. The relationship of respiratory and cardiovascular hospital admissions to the southern California wildfires of 2003. Occup Environ Med. 2009;66:189-97.

45. Hutchinson JA, Vargo J, Milet M, French NHF, Billmire M, Johnson J, et al. The San Diego 2007 wildfires and Medi-Cal emergency department presentations, inpatient hospitalizations, and outpatient visits: An observational study of smoke exposure periods and a bidirectional case-crossover analysis. PLoS Med. 2018;15:e1002601.

46. Stowell JD, Geng G, Saikawa E, Chang HH, Fu J, Yang C-E, et al. Associations of wildfire smoke PM2.5 exposure with cardiorespiratory events in Colorado 2011-2014. Environ Int. 2019;133:105151. 
47. Borchers Arriagada N, Horsley JA, Palmer AJ, Morgan GG, Tham R, Johnston FH. Association between fire smoke fine particulate matter and asthma-related outcomes: Systematic review and meta-analysis. Environ Res. 2019;179:108777.

48. Kondo MC, De Roos AJ, White LS, Heilman WE, Mockrin MH, Gross-Davis CA et al. Meta-analysis of heterogeneity in the effects of wildfire smoke exposure on respiratory health in North America. Int J Environ Res Public Health. 2019;16. https://doi. org/10.3390/ijerph16060960.

49. Henderson Sarah B, Brauer M, MacNab Ying C, Kennedy Susan M. Three measures of forest fire smoke exposure and their associations with respiratory and cardiovascular health outcomes in a population-based cohort. Environ Health Perspect. 2011;119:1266-71.

50. Morgan G, Sheppeard V, Khalaj B, Ayyar A, Lincoln D, Jalaludin B, et al. Effects of bushfire smoke on daily mortality and hospital admissions in Sydney, Australia. Epidemiology. 2010;21:47-55.

51. Jalaludin B, Smith M, O'Toole B, Leeder S. Acute effects of bushfires on peak expiratory flow rates in children with wheeze: a time series analysis. Aust NZ J Public Health. 2000;24:174-7.

52. Künzli N, Avol E, Wu J, Gauderman WJ, Rappaport E, Millstein J, et al. Health effects of the 2003 Southern California wildfires on children. Am J Respir Crit Care Med. 2006;174:1221-8.

53. Leibel S, Nguyen M, Brick W, Parker J, Ilango S, Aguilera R, et al. Increase in pediatric respiratory visits associated with Santa Ana wind-driven wildfire smoke and $\mathrm{PM}_{2.5}$ levels in San Diego County. Ann Am Thorac Soc. 2020;17:313-20.

54. Vicedo-Cabrera AM, Esplugues A, Iñíguez C, Estarlich M, Ballester F. Health effects of the 2012 Valencia (Spain) wildfires on children in a cohort study. Environ Geochem Health. 2016;38:703-12.

55. Johnston DFH, Webby RJ, Pilotto LS, Bailie RS, Parry DL, Halpin SJ. Vegetation fires, particulate air pollution and asthma: a panel study in the Australian monsoon tropics. Int J Environ Health Res. 2006;16:391-404.

56. Huang R, Hu Y, Russell AG, Mulholland JA, Odman MT. The impacts of prescribed fire on PM2.5 air quality and human health: application to asthma-related emergency room visits in Georgia, USA. Int J Environ Res Public Health. 2019;16:2312.

57. Abdo M, Ward I, O'Dell K, Ford B, Pierce JR, Fischer EV, et al. Impact of wildfire smoke on adverse pregnancy outcomes in Colorado, 2007-2015. Int J Environ Res Public Health. 2019;16:3720.

58. Holstius David M, Reid Colleen E, Jesdale Bill M, MorelloFrosch Rachel. Birth weight following pregnancy during the 2003 Southern California Wildfires. Environ Health Perspect. 2012;120:1340-5.

59. Smith C, Ryckman K, Barnabei VM, Howard B, Isasi CR, Sarto $\mathrm{G}$, et al. The impact of birth weight on cardiovascular disease risk in the Women's Health Initiative. Nutr Metab Cardiovasc Dis. 2016;26:239-45.

60. Jones RT, Ribbe DP, Cunningham PB, Weddle JD, Langley AK. Psychological impact of fire disaster on children and their parents. Behav Modif. 2002;26:163-86.

61. Brown MRG, Agyapong V, Greenshaw AJ, Cribben I, BrettMacLean P, Drolet J, et al. After the Fort McMurray wildfire there are significant increases in mental health symptoms in grade 7-12 students compared to controls. BMC Psychiatry. 2019;19:18.

62. Brown MRG, Agyapong V, Greenshaw AJ, Cribben I, BrettMacLean P, Drolet J et al. Significant PTSD and other mental health effects present 18 months after the fort mcmurray wildfire: findings from 3070 Grades 7-12 Students. Front Psychiatry. 2019;10. https://doi.org/10.3389/fpsyt.2019.00623.
63. Felix E, Afifi T, Kia-Keating M, Brown L, Afifi W, Reyes G. Family functioning and posttraumatic growth among parents and youth following wildfire disasters. Am J Orthopsychiatry. 2015;85:191-200.

64. McDermott BM, Lee EM, Judd M, Gibbon P. Posttraumatic stress disorder and general psychopathology in children and adolescents following a wildfire disaster. Can J Psychiatry. 2005;50:137-43.

65. Bryant RA, Gibbs L, Gallagher HC, Pattison P, Lusher D, MacDougall $\mathrm{C}$, et al. Longitudinal study of changing psychological outcomes following the Victorian Black Saturday bushfires. Aust NZ J Psychiatry. 2018;52:542-51.

66. Ja M, P M, D M, Sc R, Em S, C G-C, et al. Wildland forest fire smoke: health effects and intervention evaluation, Hoopa, California, 1999. West J Med. 2002;176:157-62.

67. US EPA O. Evaluation of emerging air sensor performance. US EPA; 2016, https://www.epa.gov/air-sensor-toolbox/evaluationemerging-air-sensor-performance. Accessed 9 Apr 2020.

68. South Coast Air Quality Management District. Air quality sensor summary reports. http://www.aqmd.gov/aq-spec/evaluations/ summary-pm. Accessed 9 Jul 2020.

69. Pearson C. Phone call with Charles Pearson of the California Air Resources Board; 2020.

70. Stone S. Email from Susan Stone at US EPA; 2020.

71. Delp WW, Singer BC. Wildfire smoke adjustment factors for low-cost and professional pm2.5 monitors with optical sensors. Sensors. 2020;20:3683.

72. Johnson D. Phone call with Daniel Johnson of the Oregon Department of Environmental Quality; 2020.

73. AQI. Basic AirNow.gov. https://www.airnow.gov/aqi/aqi-basics/. Accessed 13 May 2020.

74. Mintz D, Stone S, Dickerson P, Davis A. Transitioning to a new NowCast Method; 2013. https://www3.epa.gov/airnow/ani/ pm25_aqi_reporting_nowcast_overview.pdf. Accessed 7 May 2020.

75. Ogletree M. Phone call with Michael Ogletree of the Denver Department of Public Health and Environment; 2020.

76. Denver Public Health and Environment. Love my air: Denver Public Health and Environment. http://www.denveraq.com/. Accessed 24 Mar 2020.

77. US EPA O. FAQs: Pilot "Sensor Scale" project to communicate instantaneous air quality data. US EPA; 2016. https://www.epa. gov/air-research/faqs-pilot-sensor-scale-project-communicateinstantaneous-air-quality-data. Accessed 9 Apr 2020.

78. OSHA. Respiratory infection control: respirators versus surgical masks. https://www.osha.gov/Publications/OSHA3219.pdf.

79. 3M. Respiratory protection FAQ: general public. $3 \mathrm{M}$; 2020. https://multimedia.3m.com/mws/media/17932790/3m-a nz-2020-respiratory-protection-faqs-general-public.pdf. Accessed 9 Apr 2020.

80. Rengasamy S, Eimer B, Shaffer RE. Simple respiratory protection-evaluation of the filtration performance of cloth masks and common fabric materials against $20-1000 \mathrm{~nm}$ size particles. Ann Occup Hyg. 2010;54:789-98.

81. Jones JG. The physiological cost of wearing a disposable respirator. Am Ind Hyg Assoc J. 1991;52:219-25.

82. Roberge RJ, Coca A, Williams WJ, Powell JB, Palmiero AJ. Physiological impact of the N95 filtering facepiece respirator on healthcare workers. Respir Care. 2010;55:569-77.

83. Rebmann T, Carrico R, Wang J. Physiologic and other effects and compliance with long-term respirator use among medical intensive care unit nurses. Am J Infect Control. 2013;41:1218-23.

84. Roberge RJ, Kim J-H, Powell JB, Shaffer RE, Ylitalo CM, Sebastian JM. Impact of low filter resistances on subjective and 
physiological responses to filtering facepiece respirators. PLoS ONE. 2013;8. https://doi.org/10.1371/journal.pone.0084901.

85. Harber P, Bansal S, Santiago S, Liu D, Yun D, Ng D, et al. Multidomain subjective response to respirator use during simulated work. J Occup Environ Med. 2009;51:38-45.

86. Bansal S, Harber P, Yun D, Liu D, Liu Y, Wu S, et al. Respirator physiological effects under simulated work conditions. J Occup Environ Hyg. 2009;6:221-7.

87. Roberge RJ, Kim J-H, Powell JB. N95 respirator use during advanced pregnancy. Am J Infect Control. 2014;42:1097-1100.

88. Morishita M, Wang L, Speth K, Zhou N, Bard RL, Li F, et al. Acute blood pressure and cardiovascular effects of near-roadway exposures with and without N95 respirators. Am J Hypertens. 2019;32:1054-65.

89. Shi J, Lin Z, Chen R, Wang C, Yang C, Cai J, et al. Cardiovascular benefits of wearing particulate-filtering respirators: a randomized crossover trial. Environ Health Perspect. 2017; 125:175-80.

90. Patel D, Shibata T, Wilson J, Maidin A. Challenges in evaluating PM concentration levels, commuting exposure, and mask efficacy in reducing PM exposure in growing, urban communities in a developing country. Sci Total Environ. 2016;543:416-24.

91. Mueller W, Horwell CJ, Apsley A, Steinle S, McPherson S, Cherrie JW, et al. The effectiveness of respiratory protection worn by communities to protect from volcanic ash inhalation. Part I: Filtration efficiency tests. Int J Hyg Environ Health. 2018;221:967-76.

92. Dato VM, Hostler D, Hahn ME. Simple respiratory mask. Emerg Infect Dis. 2006;12:1033-4.

93. Davies A, Thompson K-A, Giri K, Kafatos G, Walker J, Bennett A. Testing the efficacy of homemade masks: would they protect in an influenza pandemic? Disaster Med Public Health Prep. 2013;7:413-8.

94. Shakya KM, Noyes A, Kallin R, Peltier RE. Evaluating the efficacy of cloth facemasks in reducing particulate matter exposure. J Expo Sci Environ Epidemiol. 2017;27:352-7.

95. Bowen LE. Does that face mask really protect you? Appl Biosaf. 2010. https://doi.org/10.1177/153567601001500204.

96. Duling MG, Lawrence RB, Slaven JE, Coffey CC. Simulated workplace protection factors for half-facepiece respiratory protective devices. J Occup Environ Hyg. 2007;4:420-31.

97. Oberg T, Brosseau LM. Surgical mask filter and fit performance. Am J Infect Control. 2008;36:276-82.

98. Jung H, Kim JK, Lee S, Lee J, Kim J, Tsai P, et al. Comparison of filtration efficiency and pressure drop in anti-yellow sand masks, quarantine masks, medical masks, general masks, and handkerchiefs. Aerosol Air Qual Res. 2014;14:991-1002.

99. Langrish JP, Mills NL, Chan JK, Leseman DL, Aitken RJ, Fokkens PH, et al. Beneficial cardiovascular effects of reducing exposure to particulate air pollution with a simple facemask. Part Fibre Toxicol. 2009;6:8.

100. Sande M, van der Teunis P, Sabel R. Professional and homemade face masks reduce exposure to respiratory infections among the general population. PLoS ONE. 2008;3:e2618.

101. Grinshpun SA, Haruta H, Eninger RM, Reponen T, McKay RT, Lee S-A. Performance of an N95 filtering facepiece particulate respirator and a surgical mask during human breathing: two pathways for particle penetration. J Occup Environ Hyg. 2009;6:593-603.

102. Coffey CC, Lawrence RB, Campbell DL, Zhuang Z, Calvert CA, Jensen PA. Fitting characteristics of eighteen N95 filteringfacepiece respirators. J Occup Environ Hyg. 2004;1:262-71.

103. Guan T, Hu S, Han Y, Wang R, Zhu Q, Hu Y, et al. The effects of facemasks on airway inflammation and endothelial dysfunction in healthy young adults: a double-blind, randomized, controlled crossover study. Part Fibre Toxicol. 2018;15. https:// doi.org/10.1186/s12989-018-0266-0.

104. Langrish JP, Li X, Wang S, Lee MMY, Barnes GD, Miller MR, et al. Reducing personal exposure to particulate air pollution improves cardiovascular health in patients with coronary heart disease. Environ Health Perspect. 2012;120:367-72.

105. Guha S, McCaffrey B, Hariharan P, Myers MR. Quantification of leakage of sub-micron aerosols through surgical masks and facemasks for pediatric use. J Occup Environ Hyg. 2017;14:214-23.

106. Harber P, Boumis RJ, Su J, Barrett S, Alongi G. Comparison of three respirator user training methods. J Occup Environ Med. 2013;55:1484-8.

107. National Institute for Occupational Safety and Health. Nonoccupational Uses of Respiratory Protection-What Public Health Organizations and Users Need to Know | | Blogs | CDC. https://blogs.cdc.gov/niosh-science-blog/2018/01/04/respiratorspublic-use/. Accessed 9 Apr 2020.

108. Goh DYT, Mun MW, Lee WLJ, Teoh OH, Rajgor DD. A randomised clinical trial to evaluate the safety, fit, comfort of a novel N95 mask in children. Sci Rep. 2019;9:1-10.

109. McCullough N, Betsinger G. Conference call with Nikki McCullough and Geoff Betsinger of 3M; 2020.

110. US EPA O. NAAQS Table. US EPA; 2014. https://www.epa. gov/criteria-air-pollutants/naaqs-table. Accessed 16 Mar 2020.

111. US EPA O. Creating healthy indoor air quality in schools. US EPA; 2014. https://www.epa.gov/iaq-schools. Accessed 9 Apr 2020.

112. Meng QY, Spector D, Colome S, Turpin B. Determinants of indoor and personal exposure to PM2.5 of indoor and outdoor origin during the RIOPA study. Atmos Environ Oxf Engl 1994. 2009;43:5750-8.

113. Kim S, Hong S-H, Bong C-K, Cho M-H. Characterization of air freshener emission: the potential health effects. J Toxicol Sci. 2015;40:535-50.

114. Chan WR, Parthasarathy S, Fisk WJ, McKone TE. Estimated effect of ventilation and filtration on chronic health risks in U.S. offices, schools, and retail stores. Indoor Air. 2016;26:331-43.

115. Batterman S, Su F-C, Wald A, Watkins F, Godwin C, Thun G. Ventilation rates in recently constructed U.S. school classrooms. Indoor Air. 2017;27:880-90.

116. Fisk WJ. The ventilation problem in schools: literature review. Indoor Air. 2017;27:1039-51.

117. Chan WR, Li X, Singer BC, Pistochini T, Vernon D, Outcault S, et al. Ventilation rates in California classrooms: why many recent HVAC retrofits are not delivering sufficient ventilation. Build Environ. 2020;167:106426.

118. Mendell MJ, Eliseeva EA, Davies MM, Spears M, Lobscheid A, Fisk WJ, et al. Association of classroom ventilation with reduced illness absence: a prospective study in California elementary schools. Indoor Air. 2013;23:515-28.

119. Wargocki P, Wyon DP. The effects of moderately raised classroom temperatures and classroom ventilation rate on the performance of schoolwork by children (RP-1257). HVACR Res. 2007;13:193-220.

120. Roy A, Downes MJ, Wisnivesky JP. Comprehensive environmental management of asthma and pediatric preventive care. Pediatr Allergy Immunol. 2011;22:277-82.

121. Sublett JL. Effectiveness of air filters and air cleaners in allergic respiratory diseases: a review of the recent literature. Curr Allergy Asthma Rep. 2011;11:395-402.

122. Sublett JL, Seltzer J, Burkhead R, Williams PB, Wedner HJ, Phipatanakul W. Air filters and air cleaners: Rostrum by the American Academy of Allergy, Asthma \& Immunology Indoor Allergen Committee. J Allergy Clin Immunol. 2010;125:32-8. 
123. McDonald E, Cook D, Newman T, Griffith L, Cox G, Guyatt G. Effect of air filtration systems on asthma: a systematic review of randomized trials. Chest. 2002;122:1535-42.

124. Martenies SE, Batterman SA. Effectiveness of using enhanced filters in schools and homes to reduce indoor exposures to $\mathrm{PM}_{2.5}$ from outdoor sources and subsequent health benefits for children with asthma. Environ Sci Technol. 2018;52:10767-76.

125. Polidori A, Fine PM, White V, Kwon PS. Pilot study of highperformance air filtration for classroom applications. Indoor Air. 2013;23:185-95.

126. California Air Resources Board. Indoor Air Quality Research California Air Resources Board. https://ww2.arb.ca.gov/ resources/documents/indoor-air-quality-research. Accessed 24 Mar 2020

127. Pacitto A, Amato F, Moreno T, Pandolfi M, Fonseca A, Mazaheri $\mathrm{M}$, et al. Effect of ventilation strategies and air purifiers on the children's exposure to airborne particles and gaseous pollutants in school gyms. Sci Total Environ. 2020;712:135673.

128. Jhun I, Gaffin JM, Coull BA, Huffaker MF, Petty CR, Sheehan WJ, et al. School environmental intervention to reduce particulate pollutant exposures for children with asthma. J Allergy Clin Immunol Pr. 2017;5:154-159.e3.

129. Gilraine M. Air filters, pollution and student achievement; 2020, https://www.edworkingpapers.com/ai20-188. Accessed 10 Jan 2020.

130. California Air Resources Board. California Certified Air Cleaning Devices I California Air Resources Board. https://ww2.arb. ca.gov/our-work/programs/air-cleaners-ozone-products/ca lifornia-certified-air-cleaning-devices. Accessed 14 Apr 2020.

131. California Air Resources Board. Air Cleaner Information for Consumers I California Air Resources Board. https://ww2.arb.ca. gov/our-work/programs/air-cleaners-ozone-products/air-cleanerinformation-consumers. Accessed 3 Jul 2020.

132. Fisk WJ, Chan WR. Health benefits and costs of filtration interventions that reduce indoor exposure to PM2.5 during wildfires. Indoor Air. 2017;27:191-204.

133. Henderson DE, Milford JB, Miller SL. Prescribed burns and wildfires in Colorado: impacts of mitigation measures on indoor air particulate matter. J Air Waste Manag Assoc. 2005;55:1516-26.

134. Barn P, Larson T, Noullett M, Kennedy S, Copes R, Brauer M. Infiltration of forest fire and residential wood smoke: an evaluation of air cleaner effectiveness. J Expo Sci Environ Epidemiol. 2008;18:503-11.
135. Stone S. Wildfire smoke: a guide for public health officials. USEPA. 2019. https://www3.epa.gov/airnow/wildfiresmoke/wildfire-smoke-guide-revised-2019.pdf. Accessed 19 Mar 2020.

136. Office of Environmental Health Hazard Assessment of California EPA. Guidance for schools during wildfire smoke events. OEHHA. 2019. https://oehha.ca.gov/media/downloads/air/factsheet/wildfiresmokeguideschoolsada.pdf. Accessed 8 Jul 2020.

137. Washington State Department of Health. Summary guidance: wildfire smoke. https://www.doh.wa.gov/Portals/1/Documents/ 4300/334-431-WIldfireSmokeSCHOOLSummary.pdf. Accessed 24 Mar 2020.

138. Fox J. Phone call with Nancy Bernard and Julie Fox of the Washington Department of Health; 2020.

139. Fazli T, Zeng Y, Stephens B. Fine and ultrafine particle removal efficiency of new residential HVAC filters. Indoor Air. 2019;29:656-69.

140. Zaatari M, Novoselac A, Siegel J. The relationship between filter pressure drop, indoor air quality, and energy consumption in rooftop HVAC units. Build Environ. 2014;73:151-61.

141. Stampfer O. Personal Communication with Orly Stampfer, regarding an analysis she did of the publicly available data from the Pantelic et al paper; 2020.

142. Pantelic J, Dawe M, Licina D. Use of IoT sensing and occupant surveys for determining the resilience of buildings to forest fire generated PM2.5. PLoS ONE. 2019;14:e223136.

143. Laumbach R, Meng Q, Kipen H. What can individuals do to reduce personal health risks from air pollution? J Thorac Dis. 2015;7:96-107.

144. Rappold AG, Fann NL, Crooks J, Huang J, Cascio WE, Devlin $\mathrm{RB}$, et al. Forecast-based interventions can reduce the health and economic burden of wildfires. Environ Sci Technol. 2014;48:10571-9.

145. Zhang S, Li L, Gao W, Wang Y, Yao X. Interventions to reduce individual exposure of elderly individuals and children to haze: a review. J Thorac Dis. 2016;8:E62-8.

146. Fruin SA, Hudda N, Sioutas C, Delfino RJ. A predictive model for vehicle air exchange rates based on a large, representative sample. Environ Sci Technol. 2011;45:3569-75.

147. McDonald F, Horwell CJ, Wecker R, Dominelli L, Loh M, Kamanyire R, et al. Facemask use for community protection from air pollution disasters: An ethical overview and framework to guide agency decision making. Int J Disaster Risk Reduct. 2020;43:101376. 